\title{
Common fixed point results for mappings under nonlinear contraction of cyclic form in ordered metric spaces
}

Wasfi Shatanawi ${ }^{1}$ and Mihai Postolache ${ }^{2 *}$

${ }^{*}$ Correspondence:

mihai@mathem.pub.ro

2Faculty of Applied Sciences,

University Politehnica of Bucharest,

313 Splaiul Independenţei,

Bucharest, Romania

Full list of author information is

available at the end of the article

\begin{abstract}
In this paper, we introduce the notion of a cyclic $(\psi, A, B)$-contraction for the pair $(f, T)$ of self-mappings on the set $X$. We utilize our definition to introduce some common fixed point theorems for the two mappings $f$ and $T$ under a set of conditions. Also, we introduce an example to support the validity of our results. As application of our results, we derive some common fixed point theorems of integral type.
\end{abstract}

MSC: Primary 54H25; secondary $47 \mathrm{H} 10$

Keywords: metric spaces; common fixed point; altering distance function; almost contraction; ordered metric spaces; weakly increasing mappings

\section{Introduction}

In recent years many authors established interesting results in fixed point theory in (ordered) metric spaces. One of the popular topics in the fixed point theory is the cyclic contraction. Kirk et al. [1] established the first result in this interesting area. Meantime, other authors obtained important results in this area (see [1-12]).

We begin with the definition of a cyclic map.

Definition 1.1 Let $A$ and $B$ be non-empty subsets of a metric space $(X, d)$ and $T: A \cup B \rightarrow$ $A \cup B$. Then $T$ is called a cyclic map if $T(A) \subseteq B$ and $T(B) \subseteq A$.

In 2003, Kirk et al. [1] gave the following interesting theorem in fixed point theory for a cyclic map.

Theorem 1.1 ([1]) Let $A$ and $B$ be nonempty closed subsets of a complete metric space $(X, d)$. Suppose that $T: A \cup B \rightarrow A \cup B$ is a cyclic map such that

$$
d(T x, T y) \leq k d(x, y) \quad \forall x \in A, \forall y \in B
$$

If $k \in[0,1)$, then $T$ has a unique fixed point in $A \cap B$.

Recently, several authors proved many results in fixed point theory for cyclic mappings, satisfying various (nonlinear) contractive conditions (see [1-12]). Some of contractive conditions are based on functions called control functions which alter the distance between two points in a metric space. Such functions were introduced by Khan et al. [13]. 
Definition 1.2 (altering distance function, [13]) The function $\phi:[0,+\infty) \rightarrow[0,+\infty)$ is called an altering distance function if the following properties are satisfied:

(1) $\phi$ is continuous and nondecreasing;

(2) $\phi(t)=0$ if and only if $t=0$.

For some fixed point theorems based on an altering distance function, we refer the reader to $[14-20]$.

Let $X$ be a nonempty set. Then $(X, d, \preceq)$ is called an ordered metric space if and only if $(X, d)$ is a metric space and $(X, \preceq)$ is a partially ordered set. Two elements $x, y \in X$ are called comparable if $x \preceq y$ or $y \preceq x$.

Altun et al. [21, 22] introduced the notion of weakly increasing mappings and proved some existing theorems. For some works in the theory of weakly increasing mappings, we refer the reader to $[23,24]$.

Definition $1.3([21])$ Let $(X, \preceq)$ be a partially ordered set. Two mappings $F, G: X \rightarrow X$ are said to be weakly increasing if $F x \preceq G F x$ and $G x \preceq F G x$ for all $x \in X$.

The purpose of this paper is to obtain common fixed point results for mappings satisfying nonlinear contractive conditions of a cyclic form based on the notion of an altering distance function.

\section{Main result}

We start with the following definition.

Definition 2.1 Let $(X, d, \preceq)$ be an ordered metric space and $A, B$ be nonempty closed subsets of $X$. Let $f, T: X \rightarrow X$ be two mappings. The pair $(f, T)$ is called a cyclic $(\psi, A, B)$ contraction if

(1) $\psi$ is an altering distance function;

(2) $A \cup B$ has a cyclic representation w.r.t. the pair $(f, T)$; that is, $f A \subseteq B, T B \subseteq A$ and $X=A \cup B$;

(3) There exists $0<\delta<1$ such that for any comparable elements $x, y \in X$ with $x \in A$ and $y \in B$, we have

$$
\begin{aligned}
& \psi(d(f x, T y)) \\
& \quad \leq \delta \psi\left(\max \left\{d(x, y), d(x, f x), d(y, T y), \frac{1}{2}(d(x, T y)+d(f x, y))\right\}\right) .
\end{aligned}
$$

Definition 2.2 Let $(X, \preceq)$ be a partially ordered set and $A, B$ be closed subsets of $X$ with $X=A \cup B$. Let $f, T: X \rightarrow X$ be two mappings. The pair $(f, T)$ is said to be $(A, B)$-weakly increasing if $f x \preceq T f x$ for all $x \in A$ and $T x \preceq f T x$ for all $x \in B$.

From now on, by $\psi$ we mean altering distance functions unless otherwise stated. In the rest of this paper, $\mathbb{N}$ stands for the set of nonnegative integer numbers.

Theorem 2.1 Let $(X, d, \preceq)$ be an ordered complete metric space and $A, B$ be nonempty closed subsets of $X$. Let $f, T: X \rightarrow X$ be two mappings such that the pair $(f, T)$ is $(A, B)$ weakly increasing. Assume the following: 
(1) The pair $(f, T)$ is a cyclic $(\psi, A, B)$-contraction;

(2) $f$ or $T$ is continuous.

Then $f$ and $T$ have a common fixed point.

Proof Choose $x_{0} \in A$. Let $x_{1}=f x_{0}$. Since $f A \subseteq B$, we have $x_{1} \in B$. Also, let $x_{2}=T x_{1}$. Since $T B \subseteq A$, we have $x_{2} \in A$. Continuing this process, we can construct a sequence $\left\{x_{n}\right\}$ in $X$ such $x_{2 n+1}=f x_{2 n}, x_{2 n+2}=T x_{2 n+1}, x_{2 n} \in A$ and $x_{2 n+1} \in B$.

Since $f$ and $T$ are $(A, B)$-weakly increasing, we have

$$
x_{1}=f x_{0} \preceq T f x_{0}=T x_{1}=x_{2} \preceq f T x_{1}=f x_{2}=x_{3} \preceq \cdots .
$$

We divide our proof into the following steps.

Step 1: We will show that $\left\{x_{n}\right\}$ is a Cauchy sequence in $(X, d)$.

Subcase 1: Suppose that $x_{2 n}=x_{2 n+1}$ for some $n \in \mathbb{N}$. Since $x_{2 n}$ and $x_{2 n+1}$ are comparable elements in $X$ with $x_{2 n} \in A$ and $x_{2 n+1} \in B$, we have

$$
\begin{aligned}
\psi\left(d\left(x_{2 n+1}, x_{2 n+2}\right)\right)= & \psi\left(d\left(f x_{2 n}, T x_{2 n+1}\right)\right) \\
\leq & \delta \psi\left(\operatorname { m a x } \left\{d\left(x_{2 n}, x_{2 n+1}\right), d\left(x_{2 n}, f x_{2 n}\right), d\left(x_{2 n+1}, T x_{2 n+1}\right),\right.\right. \\
& \left.\left.\frac{1}{2}\left(d\left(x_{2 n}, T x_{2 n+1}\right)+d\left(f x_{2 n}, x_{2 n+1}\right)\right)\right\}\right) \\
= & \delta \psi\left(\operatorname { m a x } \left\{d\left(x_{2 n}, x_{2 n+1}\right), d\left(x_{2 n}, x_{2 n+1}\right), d\left(x_{2 n+1}, x_{2 n+2}\right),\right.\right. \\
& \left.\left.\frac{1}{2}\left(d\left(x_{2 n}, x_{2 n+2}\right)+d\left(x_{2 n+1}, x_{2 n+1}\right)\right)\right\}\right) \\
\leq & \delta \psi\left(d\left(x_{2 n+1}, x_{2 n+2}\right)\right) .
\end{aligned}
$$

Since $\delta<1$, we have $\psi\left(d\left(x_{2 n+1}, x_{2 n+2}\right)\right)=0$ and hence $x_{2 n+2}=x_{2 n+1}$. Similarly, we may show that $x_{2 n+3}=x_{2 n+2}$. Hence $\left\{x_{n}\right\}$ is a constant sequence in $X$, so it is a Cauchy sequence in $(X, d)$.

Subcase 2: $x_{2 n} \neq x_{2 n+1}$ for all $n \in \mathbb{N}$. Given $n \in \mathbb{N}$. If $n$ is even, then $n=2 t$ for some $t \in \mathbb{N}$. Since $x_{2 t} \in A, x_{2 t+1} \in B$ and $x_{2 t}, x_{2 t+1}$ are comparable, we have

$$
\begin{aligned}
& \psi\left(d\left(x_{n+1}, x_{n+2}\right)\right) \\
& =\psi\left(d\left(x_{2 t+1}, x_{2 t+2}\right)\right) \\
& =\psi\left(d\left(f x_{2 t}, T x_{2 t+1}\right)\right) \\
& \leq \delta \psi\left(\operatorname { m a x } \left\{d\left(x_{2 t}, x_{2 t+1}\right), d\left(x_{2 t}, f x_{2 t}\right), d\left(x_{2 t+1}, T x_{2 t+1}\right),\right.\right. \\
& \left.\left.\frac{1}{2}\left(d\left(x_{2 t}, T x_{2 t+1}\right)+d\left(f x_{2 t}, x_{2 t+1}\right)\right)\right\}\right) \\
& =\delta \psi\left(\max \left\{d\left(x_{2 t}, x_{2 t+1}\right), d\left(x_{2 t+1}, x_{2 t+2}\right), \frac{1}{2}\left(d\left(x_{2 t}, x_{2 t+2}\right)+d\left(x_{2 t+1}, x_{2 t+1}\right)\right)\right\}\right) \\
& \leq \delta \psi\left(\max \left\{d\left(x_{2 t}, x_{2 t+1}\right), d\left(x_{2 t+1}, x_{2 t+2}\right)\right\}\right) \text {. }
\end{aligned}
$$




$$
\max \left\{d\left(x_{2 t}, x_{2 t+1}\right), d\left(x_{2 t+1}, x_{2 t+2}\right)\right\}=d\left(x_{2 t+1}, x_{2 t+2}\right),
$$

then

$$
\psi\left(d\left(x_{2 t+1}, x_{2 t+2}\right)\right) \leq \delta \psi\left(d\left(x_{2 t+1}, x_{2 t+2}\right)\right)<\psi\left(d\left(x_{2 t+1}, x_{2 t+2}\right)\right),
$$

which is a contradiction. Thus

$$
\max \left\{d\left(x_{2 t}, x_{2 t+1}\right), d\left(x_{2 t+1}, x_{2 t+2}\right)\right\}=d\left(x_{2 t}, x_{2 t+1}\right),
$$

therefore

$$
\psi\left(d\left(x_{2 t+1}, x_{2 t+2}\right)\right) \leq \delta \psi\left(d\left(x_{2 t}, x_{2 t+1}\right)\right)
$$

If $n$ is odd, then $n=2 t+1$ for some $t \in \mathbb{N}$. Since $x_{2 t+2}$ and $x_{2 t+1}$ are comparable with $x_{2 t+2} \in A$ and $x_{2 t+1} \in B$, we have

$$
\begin{aligned}
& \psi\left(d\left(x_{n+2}, x_{n+1}\right)\right) \\
& =\psi\left(d\left(x_{2 t+3}, x_{2 t+2}\right)\right) \\
& =\psi\left(d\left(f x_{2 t+2}, T x_{2 t+1}\right)\right) \\
& \leq \delta \psi\left(\operatorname { m a x } \left\{d\left(x_{2 t+2}, x_{2 t+1}\right), d\left(x_{2 t+2}, f x_{2 t+2}\right), d\left(x_{2 t+1}, T x_{2 t+1}\right),\right.\right. \\
& \left.\left.\frac{1}{2}\left(d\left(x_{2 t+2}, T x_{2 t+1}\right)+d\left(f x_{2 t+2}, x_{2 t+1}\right)\right)\right\}\right) \\
& \leq \delta \psi\left(\max \left\{d\left(x_{2 t+2}, x_{2 t+1}\right), d\left(x_{2 t+2}, x_{2 t+3}\right), \frac{1}{2}\left(d\left(x_{2 t+2}, x_{2 t+2}\right)+d\left(x_{2 t+3}, x_{2 t+1}\right)\right)\right\}\right) \\
& \leq \delta \psi\left(\max \left\{d\left(x_{2 t+2}, x_{2 t+1}\right), d\left(x_{2 t+2}, x_{2 t+3}\right)\right\}\right) .
\end{aligned}
$$

If

$$
\max \left\{d\left(x_{2 t+2}, x_{2 t+1}\right), d\left(x_{2 t+2}, x_{2 t+3}\right)\right\}=d\left(x_{2 t+2}, x_{2 t+3}\right),
$$

then

$$
\psi\left(d\left(x_{2 t+3}, x_{2 t+2}\right)\right) \leq \delta \psi\left(d\left(x_{2 t+2}, x_{2 t+3}\right)\right)<\psi\left(d\left(x_{2 t+2}, x_{2 t+3}\right)\right),
$$

which is a contradiction. Therefore

$$
\max \left\{d\left(x_{2 t+2}, x_{2 t+1}\right), d\left(x_{2 t+2}, x_{2 t+3}\right)\right\}=d\left(x_{2 t+2}, x_{2 t+1}\right),
$$

and hence

$$
\psi\left(d\left(x_{2 t+3}, x_{2 t+2}\right)\right) \leq \delta \psi\left(d\left(x_{2 t+2}, x_{2 t+1}\right)\right) .
$$


From (2.3) and (2.5), we have

$$
\psi\left(d\left(x_{n+1}, x_{n+2}\right)\right) \leq \delta \psi\left(d\left(x_{n}, x_{n+1}\right)\right)
$$

Since $\psi$ is an altering distance function, we have $\left\{d\left(x_{n+1}, x_{n+2}\right): n \in \mathbb{N} \cup\{0\}\right\}$ is a bounded nonincreasing sequence. Thus there exists $r \geq 0$ such that

$$
\lim _{n \rightarrow+\infty} d\left(x_{n}, x_{n+1}\right)=r
$$

On letting $n \rightarrow+\infty$ in (2.6), we have

$$
\psi(r) \leq \delta \psi(r)
$$

Since $\delta<1$, we have $\psi(r)=0$ and hence $r=0$. Thus

$$
\lim _{n \rightarrow+\infty} d\left(x_{n}, x_{n+1}\right)=0
$$

Next, we show that $\left\{x_{n}\right\}$ is a Cauchy sequence in the metric space $(X, d)$. It is sufficient to show that $\left\{x_{2 n}\right\}$ is a Cauchy sequence in $(X, d)$. Suppose to the contrary; that is, $\left\{x_{2 n}\right\}$ is not a Cauchy sequence in $(X, d)$. Then there exists $\epsilon>0$ for which we can find two subsequences $\left\{x_{2 m(i)}\right\}$ and $\left\{x_{2 n(i)}\right\}$ of $\left\{x_{2 n}\right\}$ such that $n(i)$ is the smallest index for which

$$
n(i)>m(i)>i, \quad d\left(x_{2 m(i)}, x_{2 n(i)}\right) \geq \epsilon .
$$

This means that

$$
d\left(x_{2 m(i)}, x_{2 n(i)-2}\right)<\epsilon .
$$

From (2.8), (2.9) and the triangular inequality, we get that

$$
\begin{aligned}
\epsilon & \leq d\left(x_{2 m(i)}, x_{2 n(i)}\right) \leq d\left(x_{2 m(i)}, x_{2 n(i)-2}\right)+d\left(x_{2 n(i)-2}, x_{2 n(i)-1}\right)+d\left(x_{2 n(i)-1}, x_{2 n(i)}\right) \\
& <\epsilon+d\left(x_{2 n(i)-2}, x_{2 n(i)-1}\right)+d\left(x_{2 n(i)-1}, x_{2 n(i)}\right) .
\end{aligned}
$$

On letting $i \rightarrow+\infty$ in the above inequalities and using (2.7), we have

$$
\lim _{i \rightarrow+\infty} d\left(x_{2 m(i)}, x_{2 n(i)}\right)=\epsilon .
$$

Again, from (2.8) and the triangular inequality, we get that

$$
\begin{aligned}
\epsilon & \leq d\left(x_{2 m(i)}, x_{2 n(i)}\right) \\
& \leq d\left(x_{2 n(i)}, x_{2 n(i)-1}\right)+d\left(x_{2 n(i)-1}, x_{2 m(i)}\right) \\
& \leq d\left(x_{2 n(i)}, x_{2 n(i)-1}\right)+d\left(x_{2 n(i)-1}, x_{2 m(i)+1}\right)+d\left(x_{2 m(i)+1}, x_{2 m(i)}\right) \\
& \leq d\left(x_{2 n(i)}, x_{2 n(i)-1}\right)+d\left(x_{2 n(i)-1}, x_{2 m(i)}\right)+2 d\left(x_{2 m(i)+1}, x_{2 m(i)}\right) \\
& \leq 2 d\left(x_{2 n(i)}, x_{2 n(i)-1}\right)+d\left(x_{2 n(i)}, x_{2 m(i)}\right)+2 d\left(x_{2 m(i)+1}, x_{2 m(i)}\right) .
\end{aligned}
$$


Letting $i \rightarrow+\infty$ in the above inequalities and using (2.7) and (2.10), we get that

$$
\begin{aligned}
\lim _{i \rightarrow+\infty} d\left(x_{2 m(i)}, x_{2 n(i)}\right) & =\lim _{i \rightarrow+\infty} d\left(x_{2 m(i)+1}, x_{2 n(i)-1}\right) \\
& =\lim _{i \rightarrow+\infty} d\left(x_{2 m(i)+1}, x_{2 n(i)}\right) \\
& =\lim _{i \rightarrow+\infty} d\left(x_{2 m(i)}, x_{2 n(i)-1}\right) \\
& =\epsilon .
\end{aligned}
$$

Since $x_{2 m(i)}$ and $x_{2 n(i)-1}$ are comparable with $x_{2 m(i)} \in A$ and $x_{2 n(i)-1} \in B$, we have

$$
\begin{aligned}
& \psi\left(d\left(x_{2 m(i)+1}, x_{2 n(i)}\right)\right)=\psi\left(d\left(f x_{2 m(i)}, T x_{2 n(i)-1}\right)\right) \\
& \leq \delta \psi\left(\operatorname { m a x } \left\{d\left(x_{2 m(i)}, x_{2 n(i)-1}\right), d\left(x_{2 m(i)}, f x_{2 m(i)}\right), d\left(x_{2 n(i)-1}, T x_{2 n(i)-1}\right),\right.\right. \\
& \left.\left.\frac{1}{2}\left(d\left(x_{2 m(i)}, T x_{2 n(i)-1}\right)+d\left(f x_{2 m(i)}, x_{2 n(i)-1}\right)\right)\right\}\right) \\
& =\delta \psi\left(\operatorname { m a x } \left\{d\left(x_{2 m(i)}, x_{2 n(i)-1}\right), d\left(x_{2 m(i)}, x_{2 m(i)+1}\right), d\left(x_{2 n(i)-1}, x_{2 n(i)}\right),\right.\right. \\
& \left.\left.\frac{1}{2}\left(d\left(x_{2 m(i)}, x_{2 n(i)}\right)+d\left(x_{2 m(i)+1}, x_{2 n(i)-1}\right)\right)\right\}\right) \text {. }
\end{aligned}
$$

Letting $i \rightarrow+\infty$ and using the continuity of $\psi$, we get that

$$
\psi(\epsilon) \leq \delta \psi(\epsilon)
$$

Since $\delta<1$, we have $\psi(\epsilon)=0$ and hence $\epsilon=0$, a contradiction. Thus $\left\{x_{n}\right\}$ is a Cauchy sequence in $(X, d)$.

Step 2: Existence of a common fixed point.

Since $(X, d)$ is complete and $\left\{x_{n}\right\}$ is a Cauchy sequence in $X$, we have $\left\{x_{n}\right\}$ converges to some $u \in X$, that is, $\lim _{n \rightarrow \infty} d\left(x_{n}, u\right)=0$. Therefore

$$
\lim _{n \rightarrow+\infty} x_{n}=\lim _{n \rightarrow+\infty} x_{2 n-1}=\lim _{n \rightarrow+\infty} x_{2 n}=u .
$$

Since $x_{2 n}$ is a sequence in $A, A$ is closed and $x_{2 n} \rightarrow u$, we have $u \in A$. Also, since $x_{2 n+1}$ is a sequence in $B, B$ is closed and $x_{2 n+1} \rightarrow u$, we have $u \in B$. Now, we show that $u$ is a fixed point of $f$ and $T$. Without loss of generality, we may assume that $f$ is continuous, since $x_{2 n} \rightarrow u$, we get $x_{2 n+1}=f x_{2 n} \rightarrow f u$. By the uniqueness of limit, we have $u=f u$. Now, we show that $u=T u$. Since $u \preceq u$ with $u \in A$ and $u \in B$, we have

$$
\begin{aligned}
\psi(d(u, T u)) & =\psi(d(f u, T u)) \\
& \leq \delta \psi\left(\max \left\{d(f u, T u), d(u, f u), d(u, T u), \frac{1}{2}(d(u, T u)+d(f u, u))\right\}\right) \\
& =\delta \psi(d(u, T u)) .
\end{aligned}
$$

Since $\delta<1$, we get that $d(u, T u)=0$ and hence $u=T u$. 
Theorem 2.1 can be proved without assuming the continuity of $f$ or the continuity of $T$. For this instance, we assume that $X$ satisfies the following property:

(P) If $\left(x_{n}\right)$ is a nondecreasing sequence in $X$ with $x_{n} \rightarrow x$, then $x_{n} \preceq x$.

Now, we state and prove the following result.

Theorem 2.2 Let $(X, d, \preceq)$ be an ordered complete metric space and $A, B$ be nonempty closed subsets of $X$. Let $f, T: X \rightarrow X$ be two mappings such that the pair $(f, T)$ is $(A, B)$ weakly increasing. Assume the following:

(1) The pair $(f, T)$ is a cyclic $(\psi, A, B)$-contraction;

(2) $X$ satisfies property $(\mathrm{P})$.

Then $f$ and $T$ have a common fixed point.

Proof We follow the proof of Theorem 2.1 step by step to construct a nondecreasing sequence $\left(x_{n}\right)$ in $X$ with $x_{2 n} \in A, x_{2 n+1} \in B$ and $x_{2 n} \rightarrow u$ for some $u \in X$. Since $x_{2 n} \rightarrow u$, $x_{2 n+1} \rightarrow u, A$ and $B$ are closed subsets of $X$, we get $u \in A \cap B$. Using property (P), we get $x_{n} \preceq u$ for all $n \in \mathbb{N}$. Since $x_{2 n} \in A$ and $u \in B$, we have

$$
\begin{aligned}
\psi & \left(d\left(x_{2 n+1}, T u\right)\right) \\
& =\psi\left(d\left(f x_{2 n}, T u\right)\right) \\
& \leq \delta \psi\left(\left\{d\left(x_{2 n}, u\right), d\left(x_{2 n}, f x_{2 n}\right), d(u, T u), \frac{1}{2}\left(d\left(x_{2 n}, T u\right)+d\left(f x_{2 n}, u\right)\right)\right\}\right) \\
& =\delta \psi\left(\left\{d\left(x_{2 n}, u\right), d\left(x_{2 n}, x_{2 n+1}\right), d(u, T u), \frac{1}{2}\left(d\left(x_{2 n}, T u\right)+d\left(x_{2 n+1}, u\right)\right)\right\}\right) .
\end{aligned}
$$

Letting $n \rightarrow+\infty$ in the above inequality, we get $\psi(d(u, T u)) \leq \delta \psi(d(u, T u))$. Since $\delta<1$, we get $d(u, T u)=0$, hence $u=T u$. Similarly, we may show that $u=f u$. Thus $u$ is a common fixed point of $f$ and $T$.

Taking $\psi=I_{[0,+\infty)}$ (the identity function) in Theorem 2.1, we have the following result.

Corollary 2.1 Let $(X, d, \preceq)$ be an ordered complete metric space and $A, B$ be nonempty closed subsets of $X$. Let $f, T: X \rightarrow X$ be two mappings such that the pair $(f, T)$ is $(A, B)$ weakly increasing and $A \cup B$ has a cyclic representation with respect to the pair $(f, T)$. Suppose that there exists $0<\delta<1$ such that for any two comparable elements $x, y \in X$ with $x \in A$ and $y \in B$, we have

$$
d(f x, T y) \leq \delta \max \left\{d(x, y), d(x, f x), d(y, T y), \frac{1}{2}(d(x, T y)+d(f x, y))\right\} .
$$

Iff or $T$ is continuous, then $f$ and $T$ have a common fixed point.

The continuity of $f$ or $T$ in Corollary 2.1 can be dropped.

Corollary 2.2 Let $(X, d, \preceq)$ be an ordered complete metric space and $A, B$ be nonempty closed subsets of $X$. Let $f, T: X \rightarrow X$ be two mappings such that the pair $(f, T)$ is $(A, B)$ weakly increasing and such that $A \cup B$ has a cyclic representation with respect to the pair 
$(f, T)$. Suppose that there exists $0<\delta<1$ such that for any two comparable elements $x, y \in X$ with $x \in A$ and $y \in B$, we have

$$
d(f x, T y) \leq \delta \max \left\{d(x, y), d(x, f x), d(y, T y), \frac{1}{2}(d(x, T y)+d(f x, y))\right\}
$$

If $X$ satisfies property $(\mathrm{P})$, then $f$ and $T$ have a common fixed point.

By taking $f=T$ in Theorem 2.1, we have the following result.

Corollary 2.3 Let $(X, d, \preceq)$ be an ordered complete metric space and $A, B$ be nonempty closed subsets of $X$ with $X=A \cup B$. Let $f: X \rightarrow X$ be a mapping such that $f x \preceq f(f x)$ for all $x \in X$. Suppose that there exists $0<\delta<1$ such that for all $x \in A$ and $y \in B$, we have

$$
\psi(d(f x, f y)) \leq \delta \psi\left(\max \left\{d(x, y), d(x, f x), d(y, f y), \frac{1}{2}(d(x, f y)+d(f x, y))\right\}\right) .
$$

Assume the following:

(1) $f$ is a cyclic map;

(2) $f$ is continuous.

Then $f$ has a fixed point.

The continuity of $f$ in Corollary 2.3 can be dropped.

Corollary 2.4 Let $(X, d, \preceq)$ be an ordered complete metric space and $A, B$ be nonempty closed subsets of $X$ with $X=A \cup B$. Let $f: X \rightarrow X$ be a mapping such that $f x \preceq f(f x)$ for all $x \in X$. Suppose that there exists $0<\delta<1$ such that for all $x \in A$ and $y \in B$, we have

$$
\psi(d(f x, f y)) \leq \delta \psi\left(\max \left\{d(x, y), d(x, f x), d(y, f y), \frac{1}{2}(d(x, f y)+d(f x, y))\right\}\right) .
$$

Assume the following:

(1) $f$ is a cyclic map;

(2) $X$ satisfies property $(\mathrm{P})$.

Then $f$ has a fixed point.

Taking $A=B=X$ in Theorem 2.1, we have the following result.

Corollary 2.5 Let $(X, d, \preceq)$ be an ordered complete metric space. Let $f, T: X \rightarrow X$ be two weakly increasing mappings. Suppose that there exists $0<\delta<1$ such that for any two comparable elements $x, y \in X$, we have

$$
\psi(d(f x, T y)) \leq \delta \psi\left(\max \left\{d(x, y), d(x, f x), d(y, T y), \frac{1}{2}(d(x, T y)+d(f x, y))\right\}\right) .
$$

Iff or $T$ is continuous, then $f$ and $T$ have a common fixed point.

The continuity of $f$ or $T$ in Corollary 2.5 can be dropped. 
Corollary 2.6 Let $(X, d, \preceq)$ be an ordered complete metric space. Let $f, T: X \rightarrow X$ be two weakly increasing mappings. suppose that there exists $0<\delta<1$ such that for any two comparable elements $x, y \in X$, we have

$$
\psi(d(f x, T y)) \leq \delta \psi\left(\max \left\{d(x, y), d(x, f x), d(y, T y), \frac{1}{2}(d(x, T y)+d(f x, y))\right\}\right) .
$$

If $X$ satisfies property $(\mathrm{P})$, then $f$ and $T$ have a common fixed point.

To support the validity of our results, we introduce the following nontrivial example.

Example 2.1 On $X=\{0,1,2,3, \ldots\}$, consider

$$
d: X \times X \rightarrow X, \quad d(x, y)= \begin{cases}0 & \text { if } x=y \\ \max \{x, y\} & \text { if } x \neq y\end{cases}
$$

We introduce a relation on $X$ by $x \preceq y$ if and only if $y \leq x$. Define $f, T: X \rightarrow X$ by the formulae

$$
f x= \begin{cases}0 & \text { if } x=0 \\ x-1 & \text { if } x \geq 1\end{cases}
$$

and

$$
T x= \begin{cases}0 & \text { if } x=0,1,2 \\ x-3 & \text { if } x \geq 3\end{cases}
$$

Also, define $\psi:[0,+\infty) \rightarrow[0,+\infty)$ by $\psi(t)=t e^{t}$. Let $A=\{0,2,4,6, \ldots\}$ and $B=\{0,1$, $3,5, \ldots\}$. Then

(1) $(X, d, \preceq)$ is a complete ordered metric space;

(2) $A \cup B$ has a cyclic representation with respect to the pair $(f, T)$;

(3) The pair $(f, T)$ is weakly $(A, B)$-increasing;

(4) $X$ satisfies property $(\mathrm{P})$;

(5) For every two comparable elements $x, y \in X$ with $x \in A$ and $y \in B$, we have

$$
\psi(d(f x, T y)) \leq e^{-1} \psi\left(\max \left\{d(x, y), d(x, f x), d(y, T y), \frac{1}{2}(d(x, T y)+d(f x, y))\right\}\right) .
$$

Proof The proof of part (1) is clear. Since $f A=\{0,1,3,5 \ldots\} \subseteq B$ and $T B=\{0,2,4, \ldots\} \subseteq A$, we conclude that $A \cup B$ has a cyclic representation with respect to the pair $(f, T)$. To prove part (3), given $x \in A$. If $x \in\{0,1,2,3,4\}$, then $T(f x)=0$. Thus $T f x \leq f x$ and hence $f x \preceq T(f x)$. If $x \geq 5$, then $f x=x-1$ and $T(f x)=T(x-1)=x-4$. Thus $T(f x) \leq f x$ and hence $f x \preceq T(f x)$. Therefore $f x \preceq T(f x)$ for all $x \in A$. Similarly, we may show that $T x \preceq f(T x)$ for all $x \in B$. So, the pair $(f, T)$ is weakly $(A, B)$-increasing. To prove part (4), let $\left\{x_{n}\right\}$ be a nondecreasing sequence such that $x_{n} \rightarrow x \in X$. Then $d\left(x_{n}, x\right) \rightarrow d(x, x)=0$. So, $x_{n}=x$ for all $n$ except for finitely many. Since $\left(x_{n}\right)$ is a nondecreasing with respect to $\preceq$, we have $x_{1} \geq x_{2} \geq x_{3} \cdots$. Since $x_{n}=x$ for all but finitely many, then there exists $k \in \mathbb{N}$ such that $x_{1} \geq \cdots \geq x_{k-1} \geq$ 
$x_{n}=x$ for all $n \geq k$. So, $x_{n} \geq x$ for all $n \in \mathbb{N}$ and hence $x_{n} \preceq x$ for all $n \in \mathbb{N}$. Thus $X$ satisfies property (P). To prove part (5), given two comparable elements $x, y \in X$ with $x \in A$ and $y \in B$. We divide the proof into the following cases:

- Case one: $x=0$ and $y \in\{0,1,3\}$. Here, we have $f x=T y=0$ and hence $\psi(d(f x, T y))=0$.

Thus

$$
\psi(d(f x, T y)) \leq e^{-1} \psi\left(\max \left\{d(x, y), d(x, f x), d(y, T y), \frac{1}{2}(d(x, T y)+d(f x, y))\right\}\right) .
$$

- Case two: $x \geq 2$ and $y \geq 5$. Here $f x=x-1$ and $T y=y-3$. Since $x \in A$ and $y \in B$, then $x=2 t$ and $y=2 n+1$ for some $t, n \in \mathbb{N}$.

If $f x=T y$, then $x-1=y-3$ and hence $2 t-1=2 n-2$. Thus $2 t=2 n-1$, which is impossible.

If $x-1>y-3$, then $d(f x, T y)=x-1$. Thus

$$
\begin{aligned}
\psi(d(f x, T y)) & =(x-1) e^{x-1} \\
& \leq e^{-1} x e^{x} \\
& =e^{-1} \psi(x) \\
& =e^{-1} \psi(d(x, f x)) \\
& \leq e^{-1} \psi\left(\max \left\{d(x, y), d(x, f x), d(y, T y), \frac{1}{2}(d(x, T y)+d(f x, y))\right\}\right) .
\end{aligned}
$$

If $y-3>x-1$, then $d(f x, T y)=y-3$. Thus

$$
\begin{aligned}
\psi(d(f x, T y)) & =(y-3) e^{y-3} \\
& \leq e^{-3} y e^{y} \\
& \leq e^{-1} y e^{y} \\
& =e^{-1} \psi(y) \\
& =e^{-1} \psi(d(y, T y)) \\
& \leq e^{-1} \psi\left(\max \left\{d(x, y), d(x, f x), d(y, T y), \frac{1}{2}(d(x, T y)+d(f x, y))\right\}\right) .
\end{aligned}
$$

- Case three: $x=0$ and $y \geq 5$. Here $f x=0$ and $T y=y-3$. Thus

$$
\begin{aligned}
\psi(d(f x, T y)) & =\psi(y-3) \\
& =(y-3) e^{y-3} \\
& \leq e^{-1} y e^{y} \\
& =e^{-1} \psi(y) \\
& =e^{-1} \psi(d(y, T y)) \\
& \leq e^{-1} \psi\left(\max \left\{d(x, y), d(x, f x), d(y, T y), \frac{1}{2}(d(x, T y)+d(f x, y))\right\}\right) .
\end{aligned}
$$


- Case four: $x \geq 2$ and $y \in\{0,1,3\}$. Here $f x=x-1$ and $T y=0$.

$$
\begin{aligned}
\psi(d(f x, T y)) & =\psi(d(x-1,0))=\psi(x-1) \\
& =(x-1) e^{x-1} \\
& \leq e^{-1} x e^{x} \\
& =e^{-1} \psi(x) \\
& =e^{-1} \psi(d(x, f x)) \\
& \leq e^{-1} \psi\left(\max \left\{d(x, y), d(x, f x), d(y, T y), \frac{1}{2}(d(x, T y)+d(f x, y))\right\}\right) .
\end{aligned}
$$

Note that $f$ and $T$ satisfy all the hypotheses of Theorem 2.1. Hence $f$ and $T$ have a fixed point. Here 0 is the fixed point of $f$ and $T$.

\section{Applications}

Denote by $\Lambda$ the set of functions $\mu:[0,+\infty) \rightarrow[0,+\infty)$ satisfying the following hypotheses:

(h1) $\mu$ is a Lebesgue-integrable mapping on each compact of $[0,+\infty)$;

(h2) For every $\epsilon>0$, we have

$$
\int_{0}^{\epsilon} \mu(t) d t>0
$$

Theorem 3.1 Let $(X, d, \preceq)$ be an ordered complete metric space and $A, B$ be nonempty closed subsets of $X$. Let $f, T: X \rightarrow X$ be two mappings such that the pair $(f, T)$ is $(A, B)$ weakly increasing and $A \cup B$ has a cyclic representation w.r.t. the pair $(f, T)$. Suppose that there exist $\delta \in[0,1)$ and $\mu \in \Lambda$ such that for any two comparable elements $x, y \in X$ with $x \in A$ and $y \in B$, we have

$$
\int_{0}^{d(f x, T y)} \mu(s) d s \leq \delta \int_{0}^{\max \left\{d(x, y), d(x, f x), d(y, T y), \frac{1}{2}(d(x, T y)+d(f x, y))\right\}} \mu(s) d s .
$$

Iff or $T$ is continuous, then $f$ and $T$ have a common fixed point.

Proof Follows from Theorem 2.1 by defining $\psi:[0,+\infty) \rightarrow[0,+\infty)$ via $\psi(t)=\int_{0}^{t} \mu(s) d s$ and noting that $\psi$ is an altering distance function.

The continuity of $f$ or $T$ in Theorem 3.1 can be dropped.

Theorem 3.2 Let $(X, d, \preceq)$ be an ordered complete metric space and $A, B$ be nonempty closed subsets of $X$. Let $f, T: X \rightarrow X$ be two mappings such that $(f, T)$ is $(A, B)$-weakly increasing and $A \cup B$ has a cyclic representation w.r.t. the pair $(f, T)$. Suppose that there exist $\delta \in[0,1)$ and $\mu \in \Lambda$ such that for any two comparable elements $x, y \in X$ with $x \in A$ and $y \in B$, we have

$$
\int_{0}^{d(f x, T y)} \mu(s) d s \leq \delta \int_{0}^{\max \left\{d(x, y), d(x, f x), d(y, T y), \frac{1}{2}(d(x, T y)+d(f x, y))\right\}} \mu(s) d s .
$$

If $X$ satisfies property $(\mathrm{P})$, then $f$ and $T$ have a common fixed point. 
By taking $A=B=X$ in Theorems 3.1 and 3.2, we have the following results.

Corollary 3.1 Let $(X, d, \preceq)$ be an ordered complete metric space. Let $f, T: X \rightarrow X$ be two weakly increasing mappings. Suppose that there exist $\delta \in[0,1)$ and $\mu \in \Lambda$ such that for any two comparable elements $x, y \in X$, we have

$$
\int_{0}^{d(f x, T y)} \mu(s) d s \leq \delta \int_{0}^{\max \left\{d(x, y), d(x, f x), d(y, T y), \frac{1}{2}(d(x, T y)+d(f x, y))\right\}} \mu(s) d s .
$$

Iff or $T$ is continuous, then $f$ and $T$ have a common fixed point.

Corollary 3.2 Let $(X, d, \preceq)$ be an ordered complete metric space. Let $f, T: X \rightarrow X$ be two weakly increasing mappings. Suppose that there exist $\delta \in[0,1)$ and $\mu \in \Lambda$ such that for any two comparable elements $x, y \in X$, we have

$$
\int_{0}^{d(f x, T y)} \mu(s) d s \leq \delta \int_{0}^{\max \left\{d(x, y), d(x, f x), d(y, T y), \frac{1}{2}(d(x, T y)+d(f x, y))\right\}} \mu(s) d s .
$$

If $X$ satisfies property $(\mathrm{P})$, then $f$ and $T$ have a common fixed point.

\section{Competing interests}

The authors declare that they have no competing interests.

\section{Authors' contributions}

Both authors contributed equally and significantly in writing this article. Both authors read and approved the final manuscript.

\section{Author details}

'Department of Mathematics, Hashemite University, P.O. Box 150459, Zarqa, 13115, Jordan. ${ }^{2}$ Faculty of Applied Sciences, University Politehnica of Bucharest, 313 Splaiul Independenţei, Bucharest, Romania.

\section{Acknowledgements}

The authors thank the editor and the referees for their valuable comments and suggestions regarding the initial version of our article.

Received: 21 November 2012 Accepted: 26 February 2013 Published: 18 March 2013

\section{References}

1. Kirk, WA, Srinavasan, PS, Veeramani, P: Fixed points for mapping satisfying cyclical contractive conditions. Fixed Point Theory Appl. 4, 79-89 (2003)

2. Al-Thafai, MA, Shahzad, N: Convergence and existence for best proximity points. Nonlinear Anal. 70, 3665-3671 (2009)

3. Eldered, AA, Veeramani, P: Proximal pointwise contraction. Topol. Appl. 156, 2942-2948 (2009)

4. Eldered, AA, Veeramani, P: Convergence and existence for best proximity points. J. Math. Anal. Appl. 323, 1001-1006 (2006)

5. Agarwal, RP, Alghamdi, MA, Shahzad, N: Fixed point theory for cyclic generalized contractions in partial metric spaces. Fixed Point Theory Appl. 2012, Article ID 40 (2012)

6. Karapinar, E, Erhan, IM: Best proximity point on different type contractions. Appl. Math. Inf. Sci. 5, 342-353 (2011)

7. Karpagam, S, Agrawal, S: Best proximity points for cyclic Meir-Keeler contraction maps. Nonlinear Anal. 74, 1040-1046 (2011)

8. Khan, MS, Swaleh, M, Sessa, S: Fixed point theorems by altering distances between the points. Bull. Aust. Math. Soc. 30, 1-9 (1984)

9. Petruşel, G: Cyclic representations and periodic points. Stud. Univ. Babeş-Bolyai, Math. 50, 107-112 (2005)

10. Păcurar, M, Rus, IA: Fixed point theory for cyclic $\phi$-contractions. Nonlinear Anal. 72, 1181-1187 (2010)

11. Rezapour, S, Derafshpour, M, Shahzad, N: Best proximity point of cyclic $\phi$-contractions in ordered metric spaces. Topol. Methods Nonlinear Anal. 37, 193-202 (2011)

12. Shatanawi, W, Manro, S: Fixed point results for cyclic $(\psi, \phi, A, B)$-contraction in partial metric spaces. Fixed Point Theory Appl. 2012, Article ID 165 (2012)

13. Khan, MS, Swaleh, M, Sessa, S: Fixed point theorems by altering distances between the points. Bull. Aust. Math. Soc. 30, 1-9 (1984)

14. Aydi, $\mathrm{H}$, Postolache, $\mathrm{M}$, Shatanawi, W: Coupled fixed point results for $(\psi, \phi)$-weakly contractive mappings in ordered G-metric spaces. Comput. Math. Appl. 63, 298-309 (2012) 
15. Aydi, H, Karapinar, E, Shatanawi, W: Coupled fixed point results for $(\psi, \varphi)$-weakly contractive condition in ordered partial metric spaces. Comput. Math. Appl. 62, 4449-4460 (2011)

16. Cho, YJ, Rhoades, BE, Saadati, R, Samet, B, Shatanawi, W: Nonlinear coupled fixed point theorems in ordered generalized metric spaces with integral type. Fixed Point Theory Appl. 2012, Article ID 8 (2012)

17. Lakzian, $\mathrm{H}$, Samet, B: Fixed points for $(\psi, \phi)$-weakly contractive mappings in generalized metric spaces. Appl. Math. Lett. 25, 902-906 (2012)

18. Shatanawi, W, Al-Rawashdeh, A: Common fixed points of almost generalized $(\psi, \phi)$-contractive mappings in ordered metric spaces. Fixed Point Theory Appl. 2012, Article ID 80 (2012)

19. Shatanawi, W: Some fixed point results for a generalized $\psi$-weak contraction mappings in orbitally metric spaces. Chaos Solitons Fractals 45, 520-526 (2012)

20. Shatanawi, W, Samet, B: On $(\psi, \phi)$-weakly contractive condition in partially ordered metric spaces. Comput. Math. Appl. 62, 3204-3214 (2011)

21. Altun, I, Damjanović, B, Djorić, D: Fixed point and common fixed point theorems on ordered cone metric spaces. Appl. Math. Lett. 23, 310-316 (2010)

22. Altun, I, Simsek, H: Some fixed point theorems on ordered metric spaces and application. Fixed Point Theory Appl. 2010, Article ID 6214469 (2010)

23. Shatanawi, W: Some coincidence point results in cone metric spaces. Math. Comput. Model. 55, 2023-2028 (2012)

24. Shatanawi, W: Some fixed point theorems in ordered G-metric spaces and applications. Abstr. Appl. Anal. 2011, Article ID 126205 (2011)

doi:10.1186/1687-1812-2013-60

Cite this article as: Shatanawi and Postolache: Common fixed point results for mappings under nonlinear contraction of cyclic form in ordered metric spaces. Fixed Point Theory and Applications 2013 2013:60.

\section{Submit your manuscript to a SpringerOpen ${ }^{\circ}$ journal and benefit from:}

- Convenient online submission

- Rigorous peer review

- Immediate publication on acceptance

- Open access: articles freely available online

- High visibility within the field

- Retaining the copyright to your article 